\title{
Summaries of evidence: an adjunct to knowledge translation?
}

In this issue, we introduce a new article type: the summary review of evidence. The editors have collaborated with the Cochrane Nursing Group in Australia to provide summaries of evidence based on Cochrane Reviews that will be of relevance to the discipline of academic primary care across all the professions. Our first summary review (Trivedi, 2013) looks at Education for Contraceptive Use by Women after Childbirth (Lopez et al., 2012). Trivedi has identified a key topic that has important implications for women and for primary care practitioners and researchers and drawn out the evidence in summary form. As with many systematic reviews, the conclusions are not unequivocal owing to inconsistencies of quality, outcome measures and intervention types. But what can we learn from such summaries that might enhance both rapid knowledge of a subject area to be acquired, as well as inform primary care practice?

The vast majority of nurses, midwives and GPs do not have time or inclination in their daily schedules to read, digest and implement the findings from full systematic reviews. The full review is often lengthy, difficult to digest because of the range of studies under discussion and confusing for those who are unfamiliar with the techniques of meta-analysis and synthesis. Systematic reviews provide a very useful reference point for those who are developing a new service standard or policy, undertaking a research degree or indentifying gaps in the knowledge base for new research proposals, but are unlikely to be the starting point for busy practitioners who just want to improve their day-to-day practice and provide better and more effective care. The notion of evidence-based medicine (Sackett et al., 1996) has been fundamental to primary care for many years and yet we know that there are real difficulties of implementation as identified by authors such as Bryar et al. (2003), McKenna et al. (2004) and Gerrish et al. (2007).

The barriers include limited critical appraisal skills, lack of authority to change practice, lack of

(C) Cambridge University Press 2013 time and managerial support. A summary review of evidence can assist in overcoming some of the challenges of time and complexity. Through a process of distillation, the author of a summary review can apply critical appraisal skills 'by proxy' to provide a digest of the original studies under review, and to identify the key messages from the findings of the review in an accessible format that enables the time-pressed practitioner to consider the evidence in a manageable way. For example, in Trivedi's (2013) current summary review, the reader can rapidly accumulate the evidence from 11 randomised controlled trials (RCTs) of interventions to educate women about contraception in the post-partum period. From the summary, we can see, for example, that there is some evidence of effectiveness of home visits to adolescents to reduce repeat pregnancies. This evidence could be used to develop a service improvement in primary care to support young parents to manage their contraceptive needs.

However, it must be acknowledged that the concept of evidence-based practice is being reformulated in the literature so that terms such as evidence-informed decision making and knowledge translation are being commonly used to describe a process by which research findings and the knowledge that accrues from studies can be translated into the policy or practice environment. Shaw (2012) proposes that the intention of knowledge transfer is to engage the end user of the evidence in the process of informing and improving practice. Thus, the reviewer becomes a kind of 'broker' of knowledge who can act as the go-between of the practitioner or policy maker and the community, family or patient/client. The dynamic process of knowledge translation, according to Shaw (2012), includes a number of strategies that revolve around the knowledge from research transferring to the end-user, based on principles of engagement, equity of access and transparency, tailoring knowledge to user need, enhancing understanding and using interaction to enable applicability to everyday life. Clearly what 
Shaw is recognising, and providing some guidance around, is that evidence-based practice does not stop at the practitioner's hard drive. The next stage in authentic evidence-based practice is to empower the end user to make sense of knowledge to ensure that they can realise the health benefits or service improvement for themselves, or at least be in a position to make a fully informed decision about their health or health care. Summary reviews can be one step in this process, an adjunct to the knowledge-translation process. For example, from the current summary review, it would be appropriate to consider whether home visits following childbirth meet the contraceptive needs of young people, by sharing the evidence with them in an accessible and relevant format.

By providing access to the summaries of evidence to busy practitioners and decision makers, we believe there is a stronger likelihood that knowledge accumulation and transfer to those who should ultimately benefit from research could be more readily achieved.

Sally Kendall
$U K$
Email: s.kendall@herts.ac.uk

\section{References}

Bryar, R.M., Closs, S.J., Baum, G., Cooke, J., Griffiths, J., Hostick, T., Kelly, S., Knight, S., Marshall, K. and Thompson, D.R. 2003: The Yorkshire BARRIERS project: diagnostic analysis of barriers to research utilization. International Journal of Nursing Studies 40, 73-84.

Gerrish, K., Ashworth, P., Lacey, A., Bailey, J., Cooke, J., Kendall, S. and Mcneilly, E. 2007: Factors influencing the development of evidence-based practice: a research tool. Journal of Advanced Nursing 57, 328-38.

Lopez, L.M., Hiller, J.E., Grimes, D.A. and Chen, M. 2012: Education for contraceptive use by women after childbirth. Cochrane Database of Systematic Reviews 2012, Issue 8. Art. No.: CD001863. DOI: 10.1002/14651858.CD001863.pub3.

McKenna, H., Ashton, S. and Keeney, S. 2004: Barriers to evidence based practice in primary care: a review of the literature. International Journal of Nursing Studies 41, 369-78.

Trivedi, D. 2013: Cochrane review summary: education for contraceptive use by women after childbirth. Primary Health Care Research and Development 14, 109-12.

Sackett, D.L., Rosenberg, W.M.C., Gray, J.A.M., Haynes, R.B. and Richardson, W.S. 1996: Evidence based medicine: what it is and what it isn't. $B M J 312,71$.

Shaw, L. 2012: National Collaborating Centre for Methods and Tools. In Brief knowledge transfer principles. Hamilton, ON: McMaster University. Retrieved 8 January 2013 from http://www.nccmt.ca/registry/view/eng/153.html

Primary Health Care Research \& Development 2013; 14: 107-108 